\title{
Bulk heterojunction organic solar cells based on soluble poly(thienylene vinylene) derivatives
}

\author{
Claudio Girotto ${ }^{\mathrm{a}, \mathrm{b}, *}$, David Cheyns ${ }^{\mathrm{a}, \mathrm{b}}$, Tom Aernouts ${ }^{\mathrm{a}}$, Fateme Banishoeib ${ }^{\mathrm{c}}$, Laurence Lutsen ${ }^{\mathrm{d}}$, \\ Thomas J. Cleij ${ }^{c}$, Dirk Vanderzande ${ }^{c, d}$, Jan Genoe ${ }^{a}$, Jef Poortmans ${ }^{a, b}$, Paul Heremans ${ }^{a, b}$ \\ a IMEC vzw, Polymer and Molecular Electronics, Kapeldreef 75, B-3001 Leuven, Belgium \\ ${ }^{\mathrm{b}}$ ESAT, Katholieke Universiteit Leuven, Kasteelpark Arenberg 10, B-3001 Leuven, Belgium \\ ${ }^{\mathrm{c}}$ University of Hasselt, Institute of Material Research (IMO), Agoralaan, Building D, B-3590 Diepenbeek, Belgium \\ d IMEC, IMOMEC Division, Wetenschapspark 1, B-3590 Diepenbeek, Belgium
}

\section{A R T I C L E I N F O}

\section{Article history:}

Received 13 February 2008

Accepted 10 May 2008

Available online 29 May 2008

\section{PACS:}

84.60.Jt

73.61.Ph

78.20.Ci

Keywords:

Bulk heterojunction organic solar cells

Low bandgap polymer

PTV

Soluble derivatives

Poly-(2,5-thienylene vinylene)

\begin{abstract}
A B S T R A C T
We report on the comparison of photophysical and photovoltaic properties of three different soluble alkyl derivatives of the low bandgap poly(2,5-thienylene vinylene) (PTV), synthesized using the dithiocarbamate precursor route. The solubility of the precursor material in dichlorobenzene is enhanced by the addition of hexyl, dihexyl and dodecyl sidegroups to the polymer chain. The materials were characterized in solid state by means of absorption, ellipsometry and atomic force microscopy of films made from both the pristine alkyl-PTVs and alkyl-PTVs:([6,6]-phenyl $\mathrm{C}_{61}$-butyric acid methyl ester) (PCBM) mixtures in a 1:1 ratio. The materials showed an optical bandgap below $1.7 \mathrm{eV}$, derived from the absorption spectrum of the polymers. Field-effect transistors made of these materials showed hole mobilities in the range of $10^{-7}$ to $10^{-6} \mathrm{~cm}^{2} / \mathrm{Vs}$. Bulk heterojunction solar cells made with the polymer:PCBM blend reached efficiencies above $0.6 \%$.
\end{abstract}

(C) 2008 Elsevier B.V. All rights reserved.

\section{Introduction}

In recent years, organic photovoltaic (OPV) devices are gaining interest as power conversion efficiencies $(\eta)$ approach 5\% [1-6]. The increased efficiency achieved in the last years, together with the potential reduction of production costs that this class of devices offer, make them particularly interesting for mass-production of low-cost self-powered electronics.

Bulk heterojunction solar cells are one of the most promising concepts to produce OPV devices. These devices are composed by a mixture of two organic materials that

\footnotetext{
Corresponding author. Address: IMEC vzw, Polymer and Molecular Electronics, Kapeldreef 75, B-3001 Leuven, Belgium.

E-mail address: Claudio.Girotto@imec.be (C. Girotto).
}

are deposited from solution and act as the active layer of the solar cell. Recently, the focus of most of the research has been on the poly(3-hexylthiophene) (P3HT) and ([6,6]-phenyl $\mathrm{C}_{61}$-butyric acid methyl ester) (PCBM) mixture, as this combination can yield devices with $\eta>4 \%$ [5-7]. The absorption of P3HT, however, does not allow to optimally harvest the red part of the incident solar spectrum. Therefore, designing new materials shifted to the red and near infrared regions could be beneficial [8]. In fact, to generate more current the optical bandgap of the absorbing material should be less than $1.8 \mathrm{eV}[9,10]$.

New materials with a bandgap lower than that of P3HT have already shown that this approach can increase the efficiency of the solar cells to 5.5\% and is expected to reach values up to $7 \%[11,12]$. Other polymers with low bandgaps are under investigation, in order to broaden this class of 
materials. Poly(2,5-thienylene vinylene) (PTV) is one of these materials, and has already been employed in thin film transistors owing to its high charge carrier mobility $[13,14]$.

Various synthetic routes have been proposed in the last two decades for the PTV family, but the high reactivity of intermediates or even the monomer itself precluded the development of a reproducible, versatile and high yield polymerization process [15]. Several attempts were also conducted to synthesize alkyl-substituted PTVs [16-18], but only a few reports were focused on the photovoltaic response of these materials and these showed limited performance [19].

Nevertheless, this electron rich conjugated polymer still attracts interest due to its low oxidation potential, which should stabilize the charge-separated state and therefore be advantageous in polymer solar cells [17]. For this reason, we recently introduced the use of the dithiocarbamate (DTC) precursor route as a successful synthesis route for the PTV derivatives, demonstrating good yield, low polydispersity, low chemical defect content and satisfactory molecular weight $[15,20,21]$.

In previous reports, this material shows an onset of absorption at around $750 \mathrm{~nm}(1.65 \mathrm{eV})$ and solar cells made with this material show short-circuit currents $\left(J_{\mathrm{SC}}\right)$ up to $4 \mathrm{~mA} / \mathrm{cm}^{2}$ and an overall efficiency of $0.6 \%$, markedly higher than the values found in literature [22,23]. A more recent work shows that higher molecular weight seems to have an effect on the performance of bulk heterojunction solar cells, that could be enhanced to $0.76 \%$ [21]. In these studies, PTV depositions were typically made via a soluble precursor polymer, since PTV is not soluble and therefore not processable. After deposition, the precursor polymer was then converted with a heat treatment into the conjugated polymer by elimination of the leaving group, generally rendering it insoluble in the solid state [24].

These promising results obtained with solar cells based on the precursor material suggested to extend the DTC precursor route to side chain functionalized PTVs using lithium bis(trimethylsilyl)amide (LHMDS) in order to obtain soluble PTV derivatives $[15,20]$. The synthesis produced three derivatives consisting of either hexyl, dihexyl or dodecyl alkyl side chains (Fig. 1).

The influence of the side chain functionalization has been shown to be crucial for the characteristics of a polymer, as has been demonstrated by several studies for the

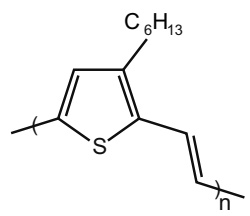

(a) Hexyl-PTV

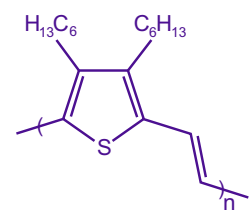

(b) Dihexyl-PTV

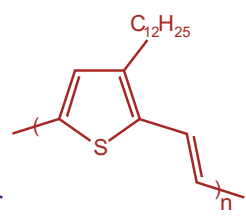

(c) Dodecyl-PTV
Fig. 1. Chemical structure of the PTV derivatives studied in this work. Three different sidegroups have been added to the PTV conjugated polymer to enhance its solubility. (a) Hexyl-PTV. (b) Dihexyl-PTV. (c) Dodecyl-PTV. poly(3-n-alkylthiophene) (P3AT) class, showing that the length of the alkyl group influences the electronic, electrochemical, and optical properties of the materials [25-27]. The focus of this paper is, then, on the comparison of the optical, electrical and solar cell devices characteristics of the three soluble PTV derivatives with different side chain we obtained from the DTC precursor route.

\section{Experimental}

\subsection{Synthesis of PTV derivatives}

The soluble alkyl-PTV derivatives used in this work were synthesized according to procedures described in literature [15]. The polymerization results of the three materials are reported in Table 1.

\subsection{Device preparation}

Solar cell structures were prepared according to the following procedure. Indium-tin-oxide (ITO) coated glass substrates, purchased from Merck Display Technologies with $20 \Omega / \square$, were first patterned and then cleaned thoroughly with a sequence of detergent, de-ionized water, acetone and boiling isopropanol, each step for $10 \mathrm{~min}$ in an ultra sonic bath. The cleaned substrates were purified further by oxygen plasma treatment with an oxygen pressure of 0.26 Torr and a power of $100 \mathrm{~W}$ for $10 \mathrm{~min}$. The substrates were then spin coated with a $0.45 \mu \mathrm{m}$ filtered poly(3,4-ethylenedioxythiophene):poly(styrenesulfonate) (PEDOT:PSS) solution, purchased from HC Starck, at $3000 \mathrm{rpm}$ for $30 \mathrm{~s}$ to produce a $30 \mathrm{~nm}$ thick layer. The substrates were subsequently heated on a hotplate in air at $120{ }^{\circ} \mathrm{C}$ for $10 \mathrm{~min}$ to remove excess water.

The further steps of the production process and the current/voltage characterization occurred in a glove box under a controlled nitrogen environment. The active layer containing a mixture of one of the PTVs derivatives and PCBM, purchased from Solenne bv, was spin coated from a dichlorobenzene solution, which was prepared under $\mathrm{N}_{2}$ environment and stirred on a hotplate at $50{ }^{\circ} \mathrm{C}$ for at least $24 \mathrm{~h}$.

$\mathrm{LiF}(0.6 \mathrm{~nm})$ and $\mathrm{Al}(100 \mathrm{~nm})$ top electrodes were deposited by thermal evaporation in ultra high vacuum $\left(10^{-8}\right.$ Torr) through a shadow mask to define eight separate cells on each substrate. The active areas were measured using an optical microscope, resulting in a range between 3.1 and $3.4 \mathrm{~mm}^{2}$.

Field-effect transistor structures were made by spin coating the organic layer on $\mathrm{n}++\mathrm{Si} / \mathrm{Al}$ substrates. The substrate itself was used as gate, with $100 \mathrm{~nm}$ of thermally

\section{Table 1}

Polymerization results for the three PTV derivatives used in this work: weight average molecular weight $\left(M_{\mathrm{w}}\right)$, number average molecular weight $\left(M_{n}\right)$ and polydispersity (PD)

\begin{tabular}{llrr}
\hline Polymer & $M_{\mathrm{w}}$ & \multicolumn{1}{c}{$M_{n}$} & PD \\
\hline Hexyl-PTV & 54,000 & 9600 & 5.6 \\
Dihexyl-PTV & 71,400 & 7700 & 9.3 \\
Dodecyl-PTV & 79,500 & 13,400 & 5.9 \\
\hline
\end{tabular}


grown oxide as gate dielectric and patterned Au source and drain electrodes in a bottom contact configuration. The channel width was $5000 \mu \mathrm{m}$, the channel length was $10 \mu \mathrm{m}$. Mobilities were extracted from the saturation regime.

\subsection{Measurements and characterization}

The photovoltaic characteristics were measured under nitrogen atmosphere using an Agilent 4156C parameter analyzer under $100 \mathrm{~mW} / \mathrm{cm}^{2}$ AM1.5 simulated illumination using a LOT-Oriel Group Europe solar simulator with a $1000 \mathrm{~W}$ Xenon arc lamp, filtered by a Newport OD 0.8 neutral density filter.

UV-visible absorption spectra were obtained using a Shimadzu UV-1601PC UV-visible spectrophotometer. Thin polymer films were spin coated onto previously cleaned quartz slides from the same solutions used for the solar cells structures. A Headway Research Inc. spin coater was used to spin coat the films at $1000 \mathrm{rpm}$ for $60 \mathrm{~s}$.

Atomic force microscopy (AFM) images were recorded on a Picoscan PicoSPM LE scanning probe microscope in tapping mode.

Ellipsometry measurements were performed with a GES5 Variable Angle Spectroscopic Ellipsometer (VASE) from SOPRA.

\section{Result and discussions}

\subsection{Solvent and spin coating parameters}

The solubility of the PTV derivatives was found to be similar for tetrahydronaphthalene and 1,2-dichlorobenzene, and both solvents showed analogous results. For this reason, 1,2-dichlorobenzene was chosen for the comparison between the three different polymers. Hexyl-PTV showed the most critical solubility, indicating that a side chain longer than hexyl was necessary to keep the polymer in solution. Solubility was enhanced only at very high solution temperatures $\left(T>150^{\circ} \mathrm{C}\right)$, but was nevertheless limited to $10 \mathrm{mg} / \mathrm{ml}$. At this concentration, particles were still visible and the solution needed to be filtered with a $0.45 \mu \mathrm{m}$ PTFE filter.

Doubling the hexyl side chain improved the solubility of the polymer: dihexyl-PTV was easily solvable up to $20 \mathrm{mg} /$ $\mathrm{ml}$ and more, showing a clear solution without aggregates. Longer side chains increased the amount of polymer that could be dissolved as well: dodecyl-PTV reached almost the same solubility level as the dihexyl-PTV, although showing a few unsolved clusters. Nevertheless, in order to keep consistency in the experiments, all these solutions underwent the same filtration process.

Due to the low polymer concentration, the viscosity of the solutions was low, limiting the choice of parameters for spin coating. In order to get a film thicknesses of approximately $100 \mathrm{~nm}$, samples had to be spin coated at a low speed of $1000 \mathrm{rpm}$, resulting in $60 \mathrm{~nm}$ thickness for the hexyl-PTV and $130 \mathrm{~nm}$ for both the dihexyl- and dodecyl-PTV.

\subsection{UV-vis absorption and ellipsometry}

The solid state optical absorption spectra of the three pristine polymers and their mixture with PCBM at 1:1 weight ratio are shown on Fig. 2.

The three polymers were dark blue and exhibited similar absorption profiles, as expected, but revealed a shift in the absorption peak $\lambda_{\max }$ from 607 (hexyl-PTV) to 622 and $630 \mathrm{~nm}$ (dodecyl- and dihexyl-PTV, respectively). The effect of the substituent appeared to be not simply steric, as longer side chains led to red-shifting of the absorption, as already observed for P3AT films [25]. The optical bandgaps confirmed the red shift for dihexyl-PTV, resulting in onsets at $739 \mathrm{~nm}(1.68 \mathrm{eV}$, hexyl- and dodecyl-PTV) and $749 \mathrm{~nm}(1.66 \mathrm{eV}$, dihexyl-PTV).

The three polymers presented prominent shoulders at energies higher than the absorption peak. Similar characteristics are found in P3HT and are typically ascribed to $\pi-\pi$ interactions $[28,29]$, thus we suggest that the PTV derivatives could be affected by significant self-organization as well. Secondary additional shoulders are present at energies lower than the absorption peak. The smooth shoulders in the spectrum of hexyl-PTV, at 577 and $684 \mathrm{~nm}$, were more pronounced in dodecyl-PTV, and even red-shifted to 583 and $693 \mathrm{~nm}$ in dihexyl-PTV. This suggested that a longer single side chain may promote solvation of the polymer, leading to expanded chain structures with longer $\pi$-conjugation lengths and improved sidechain ordering, as observed for P3ATs [25,29]. The presence of two side chains, as in the case of dihexyl-PTV, may enhance even more this property.

The addition of PCBM in hexyl-PTV did not vary the absorption of the polymer and just superimposed the absorption spectra of the two materials. When mixed to dihexyl- and dodecyl-PTV, PCBM smoothed the peaks and the shoulders of the polymer absorption spectrum, combined it with a strong absorption to the UV range, and added a constant background absorption, especially perceptible above $700 \mathrm{~nm}$. This absorption can be ascribable to light scattering induced by a nanoscale phase separation of the polymer:PCBM mixture, not visible in the

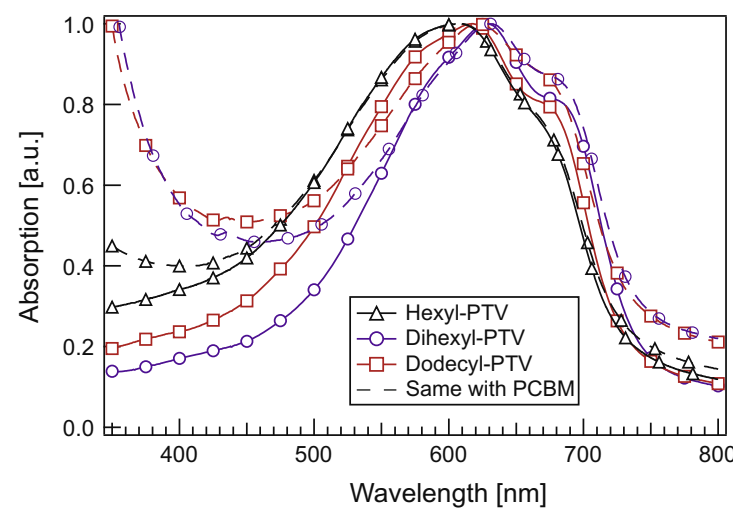

Fig. 2. Solid state absorption spectra of the three PTV derivatives and their mixtures with PCBM. Solid lines show the spectra of pristine hexylPTV $(\triangle)$, dihexyl-PTV $(\bigcirc)$ and dodecyl-PTV $(\square)$ films, while dashed lines represent their mixtures in $1: 1$ ratio with PCBM. 


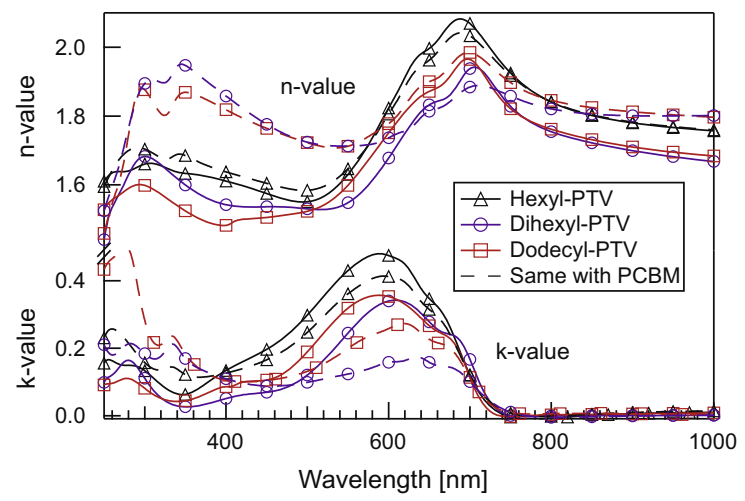

Fig. 3. Ellipsometry measurements (top: $n$-value; bottom: $k$-value) of the three PTV derivatives and their mixtures with PCBM. Solid lines show the values of pristine hexyl-PTV $(\triangle)$, dihexyl-PTV $(O)$ and dodecyl-PTV $(\square)$ films, while dashed lines represent their mixtures in 1:1 ratio with PCBM.

hexyl-PTV:PCBM film, due to its homogeneity. Since morphology of the active layer is crucial for high efficiency solar cells, these differences could already suggest that the device performance would be seriously affected by the miscibility of the PTV derivatives with PCBM.

The ellipsometry measurements shown in Fig. 3 confirmed the results obtained from UV-vis spectra, showing a red shift in the $k$-value with the same trend above mentioned. Noticeably, favored by the intrinsic characteristics of ellipsometry, the scattering component measured with UV-vis spectroscopy in the case of dihexyl- and dodecylPTV mixed with PCBM was not present in these measurements, confirming that this signal is derived from the nanoscale intermixing of the blend rather then being a property of the materials themselves. Additional information could be drawn concerning the absorption coefficient, equal for pristine dihexyl-PTV and dodecyl-PTV and markedly higher for hexyl-PTV. The cause of this difference could be ascribed again to the introduction of the inert alkyl substituent with increased segmental volume, resulting in a dilution of the polymer backbone concentration in the film [30]. Considering the mixtures in PCBM, this effect gave noticeable reduction of the extinction coefficient $k$ in the case of dihexyl- and dodecyl-PTV.

\subsection{AFM imaging}

Morphology analysis of films obtained from spin coating of pristine polymers and polymers:PCBM mixtures by AFM is reported in Figs. 4 and 5, respectively. Small differences in the morphology of the films were noticed for the three different polymers. The film composed of hexyl-PTV (root mean square roughness $($ RMS $)=0.36 \mathrm{~nm}$ ) was smoother than the films of dodecyl-PTV (RMS $=0.76 \mathrm{~nm}$ ) and that of dihexyl-PTV (RMS = $1.44 \mathrm{~nm}$ ); the smooth hexyl-PTV film is indicative of an amorphous film, providing further evidence to confirm the effect of side groups to the stacking of polymer chains.

When mixed with PCBM (Fig. 5), the hexyl-PTV film shows little evidence of phase separation, which did not change substantially the surface roughness (RMS = $0.69 \mathrm{~nm})$. Dodecyl-PTV:PCBM surface morphology remained almost unvaried as compared to the pristine film (RMS $=0.85 \mathrm{~nm}$ ), and showed a slightly heterogeneous phase distribution. Dihexyl-PTV exhibited the most

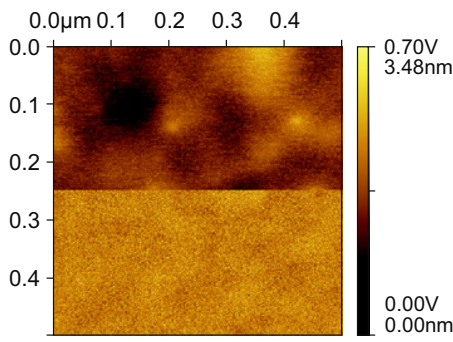

(a) Hexyl-PTV

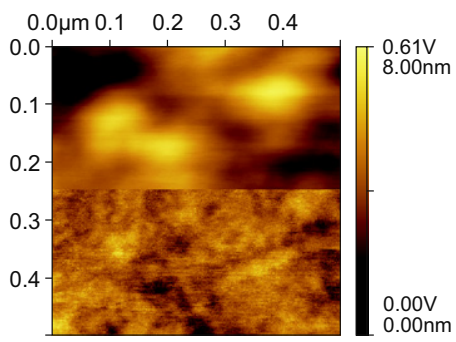

(b) Dihexyl-PTV

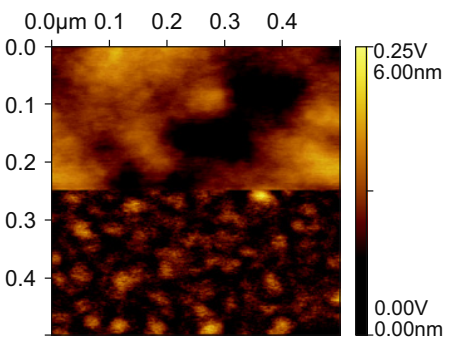

(c) Dodecyl-PTV

Fig. 4. Topography (top) and phase (bottom) atomic force microscopy scans of pristine layers of the three PTV derivatives.

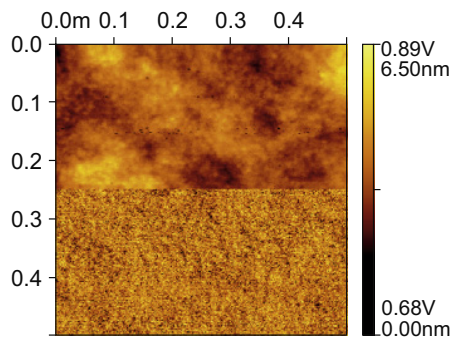

(a) Hexyl-PTV

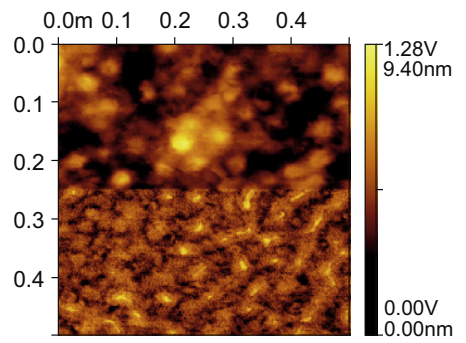

(b) Dihexyl-PTV

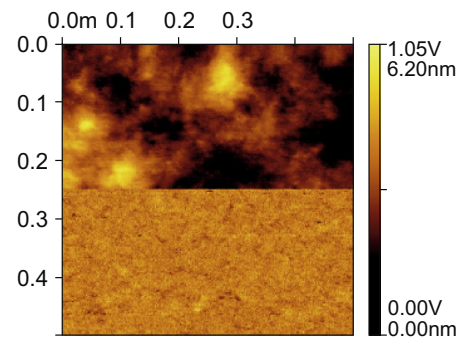

(c) Dodecyl-PTV

Fig. 5. Topography (top) and phase (bottom) atomic force microscopy scans of layers of the three PTV derivatives mixed in $1: 1$ ratio with PCBM. 
pronounced phase separation, while still keeping a homogeneous interface $(\mathrm{RMS}=1.19 \mathrm{~nm}$ ). These observations should correlate with an improvement in $J_{\mathrm{SC}}$ and efficiency for bulk heterojunction devices with dihexyl-PTV, thanks to the positive effect of segregation on charge separation and transport, as has been reported by Ma et al. for the P3HT:PCBM blend system [5].

\subsection{Current-voltage and mobility measurements}

Good transport properties of the individual composites of the active layer are important for efficient photovoltaic performance of a specific blend [11]. Hole mobility obtained from field-effect transistors is a useful measurement that facilitates the screening and development of materials that can potentially be interesting for solar cell applications [31]. Moreover, this technique has effectively been used for the characterization of P3AT with different side chain lengths to characterize the dependence of the transport properties on the alkyl group, confirming P3HT as a good candidate for OPVs due to its optimal properties $[26,27]$.

We also use this technique to verify the transport properties of both intrinsic PTV films and their mixtures with PCBM. Measurements show values in the range $10^{-5}$ to $10^{-7} \mathrm{~cm}^{2} / \mathrm{Vs}$, lower than that obtained previously with the precursor material $[13,14]$. Mobilities improve for dihexyl-PTV and dodecyl-PTV when the polymers are mixed with PCBM, increasing by values between 3 and 10, while the mobility of hexyl-PTV is decreased by the introduction of PCBM in the solution [32,33]. The complete data extracted from measurements are reported in Table 2.

Solar cells were made with the different PTV derivatives mixed with PCBM in 1:1 ratio by spin coating from dichlorobenzene solution. Every run included one sample produced with each PTV derivative and one P3HT:PCBM reference sample. From the analysis of the results, it was concluded that the best power conversion efficiency could be obtained from blends of dihexyl-PTV. Fig. 6 shows the best set of solar cells, produced with the three different PTV derivatives, measured in dark and under illumination, while Table 3 summarizes the results. Compared to the devices made by Nguyen et al., the increased open-circuit voltage $\left(V_{\mathrm{OC}}\right)$ obtained with the soluble derivatives discloses a characteristic of the conjugated polymer that was not revealed by the precursor route $[22,23]$.

Hexyl-PTV shows limitations in both current generation and extraction, being characterized by a large series resistance. The reduced thickness of the active layer $(60 \mathrm{~nm})$

Table 2

Results from field-effect transistor measurements: field-effect mobility $(\mu)$ and threshold voltage $\left(V_{\mathrm{T}}\right)$

\begin{tabular}{lll}
\hline Cell & $\mu\left[\mathrm{cm}^{2} / \mathrm{Vs}\right]$ & $V_{\mathrm{T}}[\mathrm{V}]$ \\
\hline Hexyl-PTV & $8 \times 10^{-7}$ & -5.5 \\
Dihexyl-PTV & $7 \times 10^{-6}$ & -4.6 \\
Dodecyl-PTV & $2.8 \times 10^{-6}$ & -5 \\
Hexyl-PTV:PCBM & $1.8 \times 10^{-7}$ & -6 \\
Dihexyl-PTV:PCBM & $2.3 \times 10^{-5}$ & -1.8 \\
Dodecyl-PTV:PCBM & $2.3 \times 10^{-5}$ & -0.7 \\
\hline
\end{tabular}

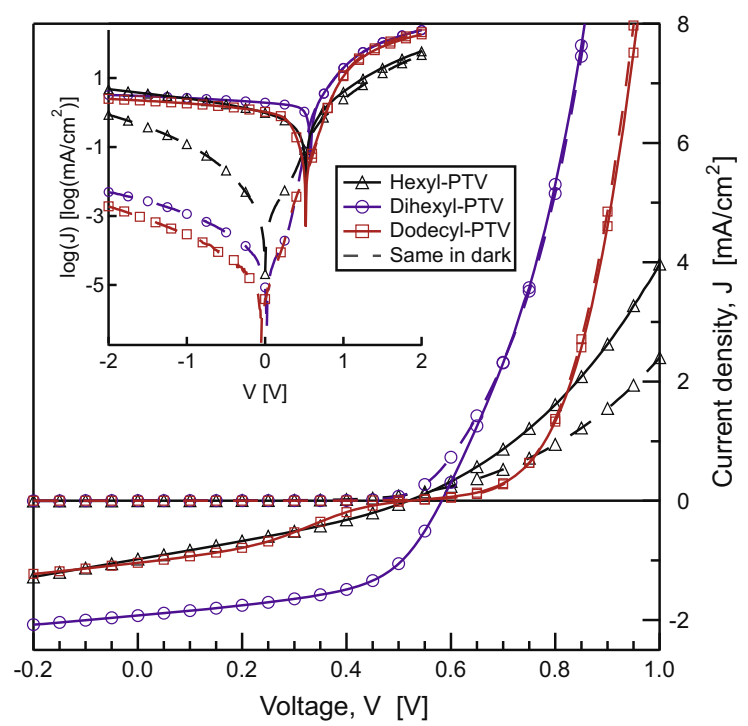

Fig. 6. The photovoltaic response of the best solar cells made with the three soluble PTV derivatives in mixture with PCBM. Solid lines show the curve under $100 \mathrm{~mW} / \mathrm{cm}^{2}$ AM1.5 simulated illumination of hexyl-PTV $(\triangle)$, dihexyl-PTV $(\bigcirc)$ and dodecyl-PTV $(\square)$ devices, while dashed lines represent their curves in dark. The inner graph shows a semi-log plot of the same curves.

Table 3

Results from photovoltaic measurements under illumination

\begin{tabular}{lllll}
\hline Cell & $V_{\mathrm{OC}}[\mathrm{mV}]$ & $J_{\mathrm{SC}}\left[\mathrm{mA} / \mathrm{cm}^{2}\right]$ & FF [\%] & $\eta[\%]$ \\
\hline Hexyl-PTV & 520 & 0.98 & 30 & 0.15 \\
Dihexyl-PTV & 580 & 1.93 & 54 & 0.61 \\
Dodecyl-PTV & 520 & 1.03 & 31 & 0.17 \\
Precursor-PTV $^{*}$ & 350 & 3.9 & 40 & 0.5 \\
\hline
\end{tabular}

is derived from the work of Nguyen et al. for a 1:1 ratio with PCBM $[22,23]$.

could explain the low short-circuit current $\left(J_{\text {sc }}\right)$, but is in contradiction with the problems in charge collection. The low mobility of the material, nevertheless, could be the limiting factor for these devices.

Dodecyl-PTV performance is characterized by an sshaped curve that limits the fill factor (FF): this is usually ascribed to a thin current-limiting layer due to impurity doping of the absorber or corrosion of the top contact [34]. Since all our samples were produced with the same procedure and were kept in the same controlled environment during the whole process, we exclude problems with the cathode and assume that the dodecyl-PTV could contain some impurities from the synthesis process or could have been contaminated by external agents before the preparation of the solutions, since the other two materials never showed this characteristic in the $i v$-curves.

Dihexyl-PTV devices are characterized by the highest $\mathrm{FF}$, above $50 \%$, and $V_{\mathrm{OC}}$, ranging between 580 and $590 \mathrm{mV}$. $J_{\mathrm{SC}}$ is still limited but improvements could be achieved with thicker depositions (actual thickness: $130 \mathrm{~nm}$ ), optimized ratio in the mixture with PCBM and enhanced morphology of the active layer at the nanoscale 
level, by thermal annealing or by varying the choice of the solvent.

\section{Conclusions}

Three different soluble PTV derivatives have been tested and their photovoltaic response has been investigated. The insoluble PTV, typically processed from its soluble precursor, has been successfully rendered soluble by the addition of three different side chains, namely a hexyl, a dihexyl and a dodecyl group.

Materials have been characterized by absorption, ellipsometry and atomic force microscopy, and field-effect transistors and solar cells have been produced. Hexyl-PTV shows a critical solubility, and its overall performances are limited to hole mobility in the order of $8 \times 10^{-7} \mathrm{~cm}^{2}$ / Vs and photovoltaic power conversion of around $0.15 \%$. Dodecyl-PTV is easily soluble up to $20 \mathrm{mg} / \mathrm{ml}$ and shows an increased hole mobility, while still demonstrating limited photovoltaic response due to possible contamination. Dihexyl-PTV is the most promising of the three materials, with a power conversion efficiency exceeding $0.6 \%$.

Further investigations could extend this first comparison between these materials to the optimization of the ratio in the mixture with PCBM in order to enhance the performance of the devices. In addition, thermal annealing treatments and the use of different solvents could improve the morphology of the active layer, a crucial factor for highly efficient solar cells.

\section{Acknowledgments}

We thank the IWT SBO-project 030220 "NANOSOLAR", funded by the Institute for the Promotion of Innovation by Science and Technology in Flanders (IWT), and the "Fonds voor Wetenschappelijk Onderzoek" (FWO-Vlaanderen), for financial support. This work, as part of the European Science Foundation EUROCORES Programme SONS (SOHYDs) was also supported by funds from the "Fonds voor Wetenschappelijk Onderzoek" (FWO-Vlaanderen) and the EC Sixth Framework Programme, under Contract N. ERAS-CT-2003-980409.

\section{References}

[1] J. Xue, B.P. Rand, S. Uchida, S.R. Forrest, A hybrid planar-mixed molecular heterojunction photovoltaic cell, Adv. Mater. 17 (1) (2005) 66-71.

[2] J. Drechsel, B. Maennig, F. Kozlowski, M. Pfeiffer, K. Leo, H. Hoppe, Efficient organic solar cells based on a double p-i-n architecture using doped wide-gap transport layers, Appl. Phys. Lett. 86 (2005) 244102.

[3] H.H.P. Gommans, D. Cheyns, T. Aernouts, C. Girotto, J. Poortmans, P. Heremans, Electro-optical study of subphthalocyanine in a bilayer organic solar cell, Adv. Funct. Mater. 17 (15) (2007) 2653-2658.

[4] B.P. Rand, J. Genoe, P. Heremans, J. Poortmans, Solar cells utilizing small molecular weight organic semiconductors, Prog. Photovoltaics 15 (2007) 659-676.

[5] W. Ma, C. Yang, X. Gong, K. Lee, A.J. Heeger, Thermally stable, efficient polymer solar cells with nanoscale control of the interpenetrating network morphology, Adv. Funct. Mater. 15 (2005) 1617-1622.

[6] J.Y. Kim, K. Lee, N.E. Coates, D. Moses, T.-Q. Nguyen, M. Dante, A.J. Heeger, Efficient tandem polymer solar cells fabricated by allsolution processing, Science 317 (5835) (2007) 222-225.
[7] G. Li, V. Shrotriya, J. Huang, Y. Yao, T. Moriarty, K. Emery, Y. Yang, High-efficiency solution processable polymer photovoltaic cells by self-organization of polymer blends, Nat. Mater. 4 (2005) 864-868.

[8] C. Winder, N.S. Sariciftci, Low bandgap polymers for photon harvesting in bulk heterojunction solar cells, J. Mater. Chem. 14 (7) (2004) 1077-1086.

[9] M.C. Scharber, D. Mühlbacher, M. Koppe, P. Denk, C. Waldauf, A.J. Heeger, C.J. Brabec, Design rules for donors in bulk-heterojunction solar cells - towards $10 \%$ energy-conversion efficiency, Adv. Mater. 18 (2006) 789-794.

[10] E. Bundgaard, F.C. Krebs, Low band gap polymers for organic photovoltaics, Sol. Energy Mater. Sol. Cells 91 (11) (2007) 954985.

[11] D. Mühlbacher, M. Scharber, M. Morana, Z. Zhu, D. Waller, R. Gaudiana, C.J. Brabec, High photovoltaic performance of a lowbandgap polymer, Adv. Mater. 18 (21) (2006) 2884-2889.

[12] J. Peet, J.Y. Kim, N.E. Coates, W.L. Ma, D. Moses, A.J. Heeger, G.C. Bazan, Efficiency enhancement in low-bandgap polymer solar cells by processing with alkane dithiols, Nat. Mater. 6 (7) (2007) 497500 .

[13] H.E.A. Huitema, G.H. Gelinck, J.B.P.H. van der Putten, K.E. Kuijk, K.M. Hart, E. Cantatore, P.T. Herwig, van Breemen, D.M. de Leeuw, Plastic transistors in active-matrix displays, Nature 414 (2001) 599.

[14] H.E.A. Huitema, G.H. Gelinck, J.B.P.H. van der Putten, K.E. Kuijk, K.M. Hart, E. Cantatore, D.M. de Leeuw, Active-matrix displays driven by solution processed polymeric transistors, Adv. Mater. 14 (17) (2002) 1201-1204.

[15] F. Banishoeib, P. Adriaensens, S. Berson, S. Guillerez, O. Douheret, J.V. Manca, S. Fourier, T.J. Cleij, L. Lutsen, D. Vanderzande, The synthesis of regio-regular poly(3-alkyl-2,5-thienylene vinylene) derivatives using lithium bis(trimethylsilyl)amide (LHMDS) in the dithiocarbamate precursor route, Sol. Energy Mater. Sol. Cells 91 (11) (2007) 1026-1034.

[16] R.S. Loewe, R.D. McCullough, Effects of structural regularity on the properties of poly(3-alkylthienylenevinylenes), Chem. Mater. 12 (10) (2000) 3214-3221.

[17] K. Van De Wetering, C. Brochon, C. Ngov, G. Hadziioannou, Design and synthesis of a low band gap conjugated macroinitiator: toward rod-coil donor-acceptor block copolymers, Macromolecules 39 (13) (2006) 4289-4297.

[18] J.J. Apperloo, C. Martineau, P.A. van Hal, J. Roncali, R.A.J. Janssen, Intra- and intermolecular photoinduced energy and electron transfer between oligothienylenevinylenes and $n$-methylfulleropyrrolidine, J. Phys. Chem. A 106 (1) (2002) 21-31.

[19] A.P. Smith, R.R. Smith, B.E. Taylor, M.F. Durstock, An investigation of poly(thienylene vinylene) in organic photovoltaic devices, Chem. Mat. 16 (23) (2004) 4687-4692.

[20] F. Banishoeib, S. Fourier, T.J. Cleij, L. Lutsen, D. Vanderzande, The synthesis of poly(thienylene vinylene) derivatives via the dithiocarbamate route: low band gap p-type conjugated polymers for photovoltaics, Eur. Phys. J. Appl. Phys 37 (2007) 237-240.

[21] F. Banishoeib, A. Henckens, S. Fourier, G. Vanhooyland, M. Breselge, J.V. Manca, T.J. Cleij, L. Lutsen, D. Vanderzande, L.H. Nguyen, H. Neugebauer, N.S. Sariciftci, Synthesis of poly(2,5-thienylene vinylene) and its derivatives: low band gap materials for photovoltaics, Thin Solid Films 516 (12) (2008) 3978-3988.

[22] L.H. Nguyen, S. Günes, H. Neugebauer, N.S. Sariciftci, F. Banishoeib, A. Henckens, T.J. Cleij, L. Lutsen, D. Vanderzande, Low-bandgap poly(thienylene vinylene) for organic solar cells: photophysics and photovoltaic performance, in: P. Heremans, M. Muccini, E.A. Meulenkamp (Eds.), Organic Optoelectronics and Photonics II. Proceedings of the SPIE, vol. 6192, 2006.

[23] L.H. Nguyen, S. Günes, H. Neugebauer, N.S. Sariciftci, F. Banishoeib, A. Henckens, T.J. Cleij, L. Lutsen, D. Vanderzande, Precursor route poly(thienylene vinylene) for organic solar cells: photophysics and photovoltaic performance, Sol. Energy Mater. Sol. Cells 90 (17) (2006) 2815-2828.

[24] A. Henckens, M. Knipper, I. Polec, J.V. Manca, L. Lutsen, D. Vanderzande, Poly(thienylene vinylene) derivatives as low band gap polymers for photovoltaic applications, Thin Solid Films 451452 (2004) 572-579.

[25] R.D. McCullough, S.P. Williams, S. Tristram-Nagle, M. Jayaraman, P.C. Ewbank, L. Miller, The first synthesis and new properties of regioregular, head-to-tail coupled polythiophenes, Synth. Met. 69 (1-3) (1995) 279-282.

[26] Y.D. Park, D.H. Kim, Y. Jang, J.H. Cho, M. Hwang, H.S. Lee, J.A. Lim, K. Cho, Effect of side chain length on molecular ordering and fieldeffect mobility in poly(3-alkylthiophene) transistors, Org. Electron. 7 (6) (2006) 514-520. 
[27] A. Babel, S.A. Jenekhe, Alkyl chain length dependence of the fieldeffect carrier mobility in regioregular poly(3-alkylthiophene)s, Synth. Met. 148 (2) (2005) 169-173.

[28] P.J. Brown, D.S. Thomas, A. Köhler, J.S. Wilson, J.-S. Kim, C.M. Ramsdale, H. Sirringhaus, R.H. Friend, Effect of interchain interactions on the absorption and emission of poly(3hexylthiophene), Phys. Rev. B 67 (6) (2003) 064203.

[29] C.-K. Shin, H. Lee, Effect of alkyl side-chain length and solvent on the luminescent characteristics of poly(3-n-alkylthiophene), Synth. Met. $140(2-3)$ (2004) 177-181.

[30] L. Liao, Y. Pang, Poly[(1,4-phenylenevinylene)-alt-(1,3-phenylenevinylene)]s with different length of side chain: their synthesis and optical properties, Synth. Met. 144 (3) (2004) 271-277.

[31] M. Morana, P. Koers, C. Waldauf, M. Koppe, D. Mühlbacher, P. Denk, M. Scharber, D. Waller, C. Brabec, Organic field-effect devices as tool to characterize the bipolar transport in polymer-fullerene blends: the case of P3HT-PCBM, Adv. Funct. Mater. 17 (16) (2007) 32743283.

[32] V.D. Mihailetchi, L.J.A. Koster, P.W.M. Blom, C. Melzer, B. de Boer, J.K.J. van Duren, R.A.J. Janssen, Compositional dependence of the performance of poly( $p$-phenylene vinylene):methanofullerene bulk-heterojunction solar cells, Adv. Funct. Mater. 15 (5) (2005) 795-801.

[33] S.M. Tuladhar, D. Poplavskyy, S.A. Choulis, J.R. Durrant, D.D.C. Bradley, J. Nelson, Ambipolar charge transport in films of methanofullerene and poly(phenylenevinylene)/methanofullerene blends, Adv. Funct. Mater. 15 (7) (2005) 1171-1182.

[34] M. Glatthaar, M. Riede, N. Keegan, K. Sylvester-Hvid, B. Zimmermann, M. Niggemann, A. Hinsch, A. Gombert, Efficiency limiting factors of organic bulk heterojunction solarcells identified by electrical impedance spectroscopy, Sol. Energy Mater. Sol. Cells 91 (5) (2007) 390-393. 